\title{
Publicidade e manipulação de identidade étnica: a imagem do japão e dos imigrantes japoneses no Brasil
}

\section{João Baptista Borges Pereira}

Unıversıdade de São Paulo São Paulo Brasıl

Unıversıdade Mackenzıc São Paulo Brasıl jborgespereura@yahoo com br 


\section{Resumo}

Com base em relatorıo elaborado por uma equipe de investigadores brasıleuros e japoneses o artigo discute como a imagem do Japao e do japonês e divulgada na America Latina principalmente no Brasil onde empresas japonesas estiveram unteressadas em produzır a dıssociação entre uma imagem do japones como umugrante nusser ou sanser geralmente associado a ruralidade $\mathrm{e}$ ao arcaismo e a do Japão tecnologicamente avançado prospero e moderno As mensagens publicitarias tendo em vista a conquista do mercado latıno americano utilızam se de estrategias para garantır uma umagem de um Japão associado a alta tecnologia modernıdade eprosperidade Dentre algumas estrategias e para atingir seus objetivos a publicidade brasileira permite pelo menos duas leituras a que admite a pluralıdade do japonês passando por cima de valores basicos do ethos ou da etnicidade nupônıca decalcados - na pratıca e na retorica - no zeloso cultivo da idesa da monorracıalıdade da nação $A$ que reafirma por outro lado a ideia geradora da pratica social historica e atual - de que os japoneses são apenas os que nasceram e cresceram em solo patrio

Palavras chave nipo brasileiros publıcıdade etnıcidade

\section{Abstract}

Based on a report elaborated by a team of Braztlian and Japanese researchers this article discusses how the tmage of Japan and of the Japanese is spread in Latin America princtpally in Brazil where the Japanese compantes were interested in disassoctating an image of the Japanese as immigrant nisset or senset generally associated with the rural and archaism from that of the technologically advanced prosperous and modern Japan The publicity messages considering the conquest of the Latm American market use strategies that guarantee an tmage of Japan associated with the modern version Among some of the strategies and in order to reach thetr objectives Brazilian publctity permits at least two readings one which admits the plurality of the Japanese rising above the basic values of the ethos or of the peasant Nipponic ethnicity - in its practice and rhetoric - to the careful cultwvation of the idea of a single race nation The second on the other hand reaffirms the productive idea of current soctal historic practice - that the Japanese are simply those who were born and raised in a single fatherland

Keynords Japanese Brazllans publictty ethnictty 


\section{Introdução}

G ste artigo baseia-se em pesquisa realizada no Brasil e na Amérıca Unuversıdade Sofıa, de Toquio, com patrocını da Fundação Toyota Seus resultados foram apresentados em um simpósıo na Unıversıdade Javeriana em Santa Fe de Bogotá, nos dias 29 e 30 de agosto de 1991 O objetıvo do sımposı for reunır todos os partıcıpantes da pesquisa para que relatassem as difıculdades, as condıções e os resultados das ınvestıgações Nessa oportunıdade, serıam trocadas opınıóes sobre o tema e comparados os resultados

A pesquisa abrangeu desde a Argentına ate o Mexıco, passando pelo Brasıl (São Paulo e Brasılıa), Colômbıa, Costa Rıca, Mexıco (Cıudad de Mexico e Tijuana, na fronterra com os EUA) ${ }^{1}$

A equipe, dirıgida pelo professor Gustavo Andrade, diretor do Instituto Iberoamericano, fol composta por pesquisadores japoneses e latino-americanos ${ }^{2}$

Neste texto, procurar-se-á seguir o seguinte roterro inıcialmente, baseados nos relatorıos dos pesquisadores e nas discussões havidas focalızar-se-ão alguns traços comuns que compõem a imagem do Japão e do japonês na Amerıca Latına colhıdos no unıverso das representações dos entrevistados Em seguıda, a analıse concentrar se-a no delineamento dessa imagem no Brasil com base em relatono da professora Ellen $\mathrm{F}$ Woortmann (UNB) ${ }^{3}$ e do autor deste artıgo $0^{4}$ Finalmente, num terceiro momento, sera focalızado o processo de manıpulação da ımagem retratada pela pesquisa por empresas japonesas Essa manıpulação é feıta por intermedıo de mensagens publıcıtárıas veıculadas, pelo menos no Brasıl pela televisão e por outdoors 


\section{Japão e japoneses na América Latına os extremos de um continuum}

A construção de um contınuum de opını̃̃es colhıdas pelas pesquısas colocarıa no polo inıcial a Argentına, país que revela grande respeito por um Japão tecnologıcamente sofıstıcado, mas, paradoxalmente, desconhecido, ou pelo menos construido com clıchês que o torna "um país exotıco' distante das experiêncıas daquela nação pretensamente mais europeizada do contınente latıno-americano No outro polo, situa-se o Méxıco, mais especıficamente Tijuana Nesse país, a umagem e francamente positıva em relação ao Japão e aos japoneses Nota-se grande preocupação em colocá-lo em pé de igualdade com os Estados Unıdos, em todos os sentıdos A Colômbıa e a Costa Rıca estão maıs próxımas das representações detectadas no Méxıco O Peru passava por uma fase excepcıonal de sua histórıa polítıca com a eleıção de Alberto Fujımorı para a Presıdêncıa da Repúblıca

A pesquisa, todavia, registra que, pelo menos nas camadas menos favorecidas do país, Fujımore era chamado de chinto O descendente de japonês era visto e avalıado, positıvamente, como membro da antıga imıgração chınesa Daí que sua figura e sua performance polıtıca não ajudavam a construur, posıtıva nem negatıvamente, a imagem do Japão e de seus descendentes no Peru

Os dados registraram, ainda, que em todos os paises pesquisados, o Japão, em maıror ou menor grau, estava associado a bens de consumo indicadores de alta tecnologia

Nesse contınuum, o Brasil expressava singularıdades que o distancıava dos polos A umagem do Japão passava obrıgatorıamente pela representação que o país fazıa dos imıgrantes e seus descendentes honestos socialmente ageıs, ambicıosos, perıgosos, pouco dados às expressões ligadas as humanidades e muito vocacionados pelo saber tecnológıco Predominava, ainda, nas opınıões, o japonês como trabalhador rural, camponês, gente rustıca, lıgada fundamentalmente a labuta agrıcola Essa opınıão era referencıada pela assocıação feıta pelos entrevistados entre imigrante japones e hortıcultor, introdutor de varnedades vegetais e frutuferas ate então desconhecıdas no pais $O$ instante revelado pela pesquisa trazıa uma ımagem de japonês profun- 
damente marcado pelo passado controverso da imıgração asıátıca Isto é, a imagem do japonês captada pela pesquisa era contaminada por residuos do que se chamou na epoca (unicio do seculo 20), de perıgo amarelo Essa imagem pretérita e congelada passava por cıma da ágıl e bem sucedıda integração do grupo a socıedade brasıleıra, vıa sıstema urbano industrıal E o Japão era avalıado atraves dessa representação que, de certa forma, se petrufıcara no umagmárı do brasıleıro

Seria interessante registrar que os pesquisadores japoneses ao sentırem-se incomodados com as avalıações argentına e brasıleira, aventaram, numa espécie de contraofensıva, a ıdeıa da exıstêncıa de uma "identıdade do Pacífıco", não encontravel nos países americanos banhados pelo Atlântico Em outras palavras, os paises americanos banhados pelo Oceano Pacifico ostentavam laços ıdentıtárıos com o dıstante Japão, ıdentıficados nas representações maıs favoráveıs ao paıs orıental Essa ıdeıa, ou hıpótese não levava em consıderação os Estados Unıdos também banhados pelo Pacıfıco Mas como a nação norte americana não fol alcançada pela pesquisa, esse pormenor for descartado sumariamente

\section{Refazendo ıdentıdade étnica o uso da mídıa}

Os resultados dessa pesquisa, pelo menos no Brasil, forneceram elementos com os quaıs empresas japonesas lançaram campanha publıcıtarıa em busca de três objetıvos

I desvincular a representação do imıgrante japonês da ımagem de um Japão atual e moderno

2 passar a umagem de um pass prospero moderno responsavel por um elenco de avanços civlizatonos ocidentaus no campo da tecnologia Estrategia que visava a contrapor o pars atual ao pass pobre e arcaico responsavel pela diaspora de japoneses no transcorrer dos seculos XIX XX

3 evitar ou anular a contammação dos modernos produtos japoneses pela representação negatıva de um imıgrante atrasado rurıcola arcaico

Essa campanha fol responsavel por quatro anuncios ou peças publicitárıas

Num primeiro anuncio (outdoor) exibia-se um aparelho de video com a segumte legenda "Se seu vıdeo não e da marca tal, então for adquirido no Jurassic Park" (Parque dos Dinossauros) Esse apelo 
publıcıtárıo associa produto japonês, alta tecnologia e vanguarda de modernudade, ao jogar os concorrentes para além dos princípıos da próprıa evolução homınıdea

Nas três mensagens publıcıtarıas dıvulgadas pela TV brasıleıra, citadas a seguur, fıca clara a preocupação em dıssociar o ımıgrante (nısseı ou sanseı) do Japão Moderno

1 caso a publicidade mostra um televisor de marca japonesa e o locutor dız os nossos japoneses são melhores que os japoneses dos outros E uma mensagem propositadamente ambigua mas que admite a existência de um Japão plural

2 caso Se no primeiro caso a frase e propositadamente ambigua agora a diferença e bem explicıtada um jovem japonês com expressão corporal cabelos roupas e cacoetes que dão o perfil estereotıpado e preconceituoso do latıno americano ballando e falando castelhano recheado de girias faz publicidade de um legitımo produto japonês O jovem e o japonês espurıo ımıgrante ja assımılado e esta alı para mostrar que a autentıcıdade e a modernudade japonesa estão no produto enunciado que e o seu contraste

3 caso doıs bebês gordos vestındo fraldas que se assemelham as roupas usadas pelos lutadores de sumô procuram curiosamente seus respec tıvos sexos Ao perceberem a diferença entre ambos soltam sonoras gargalhadas Esta publicidade permite a seguinte leitura

a) ha uma aparente semelhança entre os bebês pois ambos são da mesma origem racial

b) ha porem atras dessa semelhança ılusorıa uma duferença funda mental representada pela diferença de gênero

c) procura se ınsıstır na dıferença mas a publıcıdade reforça a marca japonesa do produto apoiando se em elementos fisıcos (traços somaticos dos bebês) e sımbolıcos (fralda tıpo sumô) represen tatıvos do Japão

\section{Conclusão}

Ao admitır a pluralıdade do japonês, os quadros publıcıtarıos permitem, pelo menos duas interpretações A prımeira mostra que a publicidade passa por cuma de valores basicos do ethos ou da etnıcıdade nıpônıca, decalcados - na prátıca e na retórıca - no zeloso cultıvo da ıdeıa da monorracialıdade da nação Três anos após a realızação da pesquısa, o mınıstro das Fınanças do Japão dızıa textualmente em entrevistas a jornais e tevês que as conquistas ou 
o progresso do país após a $2^{\mathrm{a}}$ Guerra Mundıal serıa a resultante direta do cultivo da sua monorracialıdade

Uma segunda leıtura da admıssão da pluralıdade do japonês mostra a mensagem publıcıtarıa reafırmando a ideıa geradora da pratıca social historica e atual de que os japoneses são apenas os que nasceram e cresceram em solo patrıo Os que emıgraram - ou foram obrıgados a emıgrar - e seus descendentes na diáspora são outros tıpos de criaturas que nada têm a ver com o Japão atual Os decasséguis são exemplos lımpıdos dessa ideıa e dessa pratıca sociopolıtıca Eles ostentam todas as característıcas fenotipıcas do japonês, mas não recebem o reconhe cumento, como tal, do país de seus antepassados São apenas mão de obra necessaria ao sistema produtıvo do pais asıátıco

Estıgmatuzados e discruminados, lumitam se a se locomover somente nas restritas falxas de estrutura ocupacional $O$ resto da vida japonesa the e vedado Afunal, o decassegu e o outro, o impuro a produzir a pureza do pais

\section{Notas}

1 La imagen de los latinoamencanos sobre el Japon y los jiponeses Instituto Ibero americano Universidad Sofia lokıo Serıe de monografias latıno americanas Marzo 1996 n 53 p 23

2 São os seguintes 1 Pesquisadores japoneses Shıgekı Nishıhıra (Faculdade de Clêncıas Econômıcas Unıversıdade Sofıa) Hajıme Mızuno (Faculdade de Estudos Estrangeuros e membro do Instituto Ibero Americano Universidade Sofia) Tomohuro Takayama (Faculdade de Estudos Estrangeiros e membro do Instituto Ibero Amerıcano Unıversıdade Sofia) Keıko Imaı (Faculdade de Estudos Estrangeiros e membro do Instituto Ibero Americano Unıversidade Sofia) Kotaro Horisaka (Faculdade de Estudos Estrangeiros e membro do Instituto Ibero Americano Unıversidade Sofia) Chıyoko Mita (Faculdade de Estudos Estrangeiros e membro do Instituto Ibero Americano Unıversidade Sofia) Toyoharu Tsujı (Departamento de Humanidades Universidade de Estudos Estrangerros de Kyoto) 2 Pesquisadores latino americanos Carmen Ana Hrubisko (Diretora do Estudo Hrubisko Buenos Aures) João Baptısta Borges Pereira (Faculdade de Filosofıa Letras e Ciencias Humanas Unıversidade de São Paulo São Paulo) Ellen F Woortmann (Departamento de Antropologia e Programa de Pos Graduação em Antropologıa Unıversıdade de Brasılia Brasılıa) Rafael Campo (Faculdade de Estudos Interdisciplınares Unıversıdade Javerıana Santafe de Bogota) Rodrıgo Losada (Faculdade de Estudos Interdısciplinares Universıdade Javerıana Santafe de Bogota) Manuel E Araya Incera (Faculdade Latuno americana de Ciencias Socıass São Jose) Roberto Ham Chande (Colegio da Fronteira Norte Tijuana) Jorge Sulva (Centro de Estudos de Asıa e Africa Colegıo do Mexıco Cidade do Mexico) Oscar A Mavila Marquina 
(Centro de Estudos Orientais Unıversidade Catolica do Peru Lima) Eduardo Jose Ortız F (Instıtuto de Investıgações Econômıcas e Socıaıs Unıversıdade Catolıca Andres Bello Caracas) Chı Yı Chen (Instıtuto de Investıgações Econômıcas e Sociais Unuversidade Catolica Andres Bello Caracas)

3 Woortmann E F A ımagem do Japão e dos japoneses a visão de Brasılıa In $L a$ imagen de los latinoamencanos sobre el Japon y los japoneses Op cit pp 3138

4 Borges Pereira J B Considerações sobre a imagem de japoneses e do Japão em São Paulo In La tmagen de los latinoamencanos sobre el Japon y los japoneses Op cit pp 2731 Tambem cf Borges Pereıra J B (Re) elaborações de ıdentıdades etnıcas na sociedade brasileira In Cultura planetarla opianeta multicultural Roma Domograf $1994-$ p p 481488

\section{Bibliografia}

BORGES PEREIRA J B Considerações sobre a imagem de japoneses e do Japão em São Paulo In INSTITUTO IBEROAMERICANO (Org) La imagen de los la tinoamericanos sobre el Japon y los japoneses Tokıo Universidad Sofra Marzo 1996 p 2731 (Serie de Monografias Latınoamericanas 5 3)

BORGES PEREIRA J B (Re) elaborações de identıdades etnicas na socieda de brasıleira In GIUSTI Sonıa CICCODICOLA Flonana (Org) Cultura planetaria o planeta multiculturale Roma Domograf, 1994 p 481488

DEZEM R Matızes do amarelo a gênese dos discursos sobre os orıentais no Brasıl (1878 I908) São Paulo Humanitas 2003

INSTITUTO IBEROAMERICANO (Org) La imagen de los latinoamericanos so bre el Japon y los japoneses Tokıo Universidad Sofia, Marzo 1996 (Serie de Monografias Latınoamericanas 53 )

NISHIRA S CONDOMINAS C L opinton dês japonats comparalson interna cionale Paris Sudestasie 1991

SAITO H O japonês no Brastl São Paulo Sociologia e Politıca 1961

SAITO H MAYEMA T Asstmilação e integração dos japoneses no Brasıl Petro polıs RJ Vozes São Paulo Edusp, 1973

WOORTMANN E F A umagem do Japão e dos japoneses a visão de Brasılua In INSTITUTO IBEROAMERICANO (Org) La magen de los latinoament canos sobre el Japon y los japoneses Tokıo Universidad Sofia Marzo $1996 \mathrm{p}$ 2126 (Serıe de Monogıafias I atınoamericanas 5 3) 